\title{
The Effect of Preoperative Aminophylline on the Recovery Profile After Major Pelvi-abdominal Surgeries: a Randomized Controlled Double-blinded Study
}

Samaa A. Kasim ( $\nabla$ samaarashwan1971@gmail.com )

Beni Suef University Faculty of Medicine https://orcid.org/0000-0002-3102-3438

Mahmoud Hussien Bahr

Beni-Suef University

Mohamed Abdelkader

Beni Suef University

Doaa Abu Elkassim Rashwan

Beni-Suef University: Beni Suef University

Research article

Keywords: Aminophylline, Adenosine, BIS

Posted Date: January 25th, 2021

DOl: https://doi.org/10.21203/rs.3.rs-152371/v1

License: (a) (i) This work is licensed under a Creative Commons Attribution 4.0 International License.

Read Full License

Version of Record: A version of this preprint was published at BMC Anesthesiology on April 19th, 2021. See the published version at https://doi.org/10.1186/s12871-021-01340-7. 


\section{Abstract}

Background: This study compared the effects of premedication with different doses of aminophylline on the recovery profile after general anesthesia.

Methods: 45 patients scheduled for pelvi-abdominal surgeries were divided into 3 groups; $\operatorname{Group}(\mathrm{C})$ : the patients received $100 \mathrm{ml}$ of IV normal saline, Group (A1): received $2 \mathrm{mg} / \mathrm{kg}$ aminophylline IV)and Group(A2): received $4 \mathrm{mg} / \mathrm{kg}$ aminophylline(IV)30minutes before induction of general anesthesia . The following data were recorded:demographic data, ASA physical status, duration of anesthesia and surgery, heart rate, mean arterial blood pressure, propofol dose, fentanyl dose, times to reach BIS (48 \pm 2$)$ after induction of anesthesia and to reach 80 after discontinuation of sevoflurane anesthesia,time till recovery of consciousness and to tracheal extubation and to discharge from the post-anesthesia care unit,side effects of aminophylline were also recorded .

Results :The time till BIS reach $48 \pm 2$ was statistically significantly less for the control group compared to group A2 (70.67 \pm 22.50 and $106.67 \pm 34.77$ minutes) for group $C$ and $A 2$ respectively; $(p$-value $=0.00$ ), the time till BIS reached 80 was statistically significantly longer for the control group compared to group $A 2$ (5.6 \pm 1.40 and $2.53 \pm 1.72$ minutes ) for group $C$ and $A 2$ respectively; $(p$-value $=0.00)$,time for ROC was statistically significantly longer for the control group than group A1 and A2(8.93 $\pm 0.92,5.6 \pm 2.47$ and $4.53 \pm 3.33$ minutes) for group $C, A 1$ and $A 2$ respectively ; $(p$-value $=0.00)$, the extubation time was statistically significantly longer for the control group being12.4 $\pm 1.08,7.87 \pm 3.27$ and $6.6 \pm 2.47$ minutes) for group C, A1 and A2 respectively; ( $\mathrm{p}$-value $=0.00$.

Conclusion: Premedication with aminophylline enhanced the recovery profile after pelvi-abdominal surgeries under general anesthesia without cardiovascular complications.

Trial registration: Number: NCT04151381, date November 5, 2019, retrospectively

\section{Background}

Aminophylline acts either through phosphodiesterase inhibition or by blocking adenosine receptors [1]. Aminophylline antagonizesthe effects barbiturates [2], sevoflurane [3], morphine[4]. Aminophylline delays loss of consciousness(LOC) and speeds recovery of consciousness(ROC) with propofol anesthesia,this was examined in volunteers in the study of Turan et al [5],they gave saline or aminophylline $6 \mathrm{mg} / \mathrm{kglVthen} 1.5 \mathrm{mg} / \mathrm{kg} / \mathrm{h}$ (as continuous infusion )followed by propofol $200 \mathrm{mg}$; time to LOC was prolonged and the time to ROC was shorter in aminophylline group compared with the saline group. Sakurai et al[6] presented 2 cases where $5 \mathrm{mg} / \mathrm{kg}$ aminophylline reversed propofol-induced sedation inthe postoperative period,alsothere was controversy about the optimum dose of aminophylline since toxicity was reported when it was given at high doses or as a continuous intravenous infusion [7]. Some studies suggested that low doses of aminophylline(1-2) reversed the sedation induced by benzodiazepines, barbiturates or opioids[8], other reports recommended the use of higher doses (4-6 mg/kg) for effectively awakening anesthetized patients because the lower doses produced an incomplete reversal of sedation 
or hypnosis $[1,6,9]$. So based on these knowledge and on the conclusion of Turan et al(5) that their results may differ with different patients sample or other clinical conditions and also to our knowledge aminophylline was not given as premedication to test its effect on the level of hypnosis and recovery profile after general anesthesia so this study aimed to compare the effects of premedication by different doses of aminophylline on the times of ROC, extubation time and time to discharge from the postanesthesia care unit (PACU). Its effect on the level of hypnosis ( using BIS) was also observed.

\section{Methods}

This randomized controlled double -blinded study was conducted at Beni-Suef University hospital from 20/ November/ 2019 to25/ February/ 2020 in compliance with the Helsinki Declaration after approval of the Research Ethical Committee of Beni-Suef University Hospitals (FMBSUREC/01102019/Rashwan) and obtaining written informed consent from the patients, and was registered at ClinicalTrials.gov with Identification number : NCT04151381, date November 5, 2019, retrospectively, and adheres to CONSORT guidelines, it included 45patients of both sex, in the age group 20-60 years and of American Society Of Anesthesiology physical status I- II who were scheduled for pelvi-abdominal surgeries under general anesthesia. Patients were excluded if the body mass index more than $30 \mathrm{~kg} / \mathrm{m} 2$ ),,sensitivity to aminophylline or have history of seizure, renal or hepatic impairment and coffee consumption (more than 2 cupps/day), patients with opioid addiction or treated with B agonists, tranquilizers, antidepressant were also excluded.The patients were subjected to preoperative assessment and preoperative investigations [complete blood count, coagulation profile, liver and renal function tests, chest $x$ ray and electrocardiogram (if indicated)] were done.All investigations were within normal values.0;The patients were admitted to the anesthesia preparation room where monitors were applied (pulse oximetry, 5 leads electrocardiography, noninvasive arterial blood pressure ), the heart rate(HR) and mean arterial blood pressure(MAP) were recorded before and after study drug administration, wide bore intravenous cannula was inserted and crystalloid fluid infusion was started, sedative premedication were not given to the patients and the patients were allocated randomly to three groups ( $n=15$ for each group) using sealed, opaque envelopes (indicating the group of each patient, carried out by an independent anesthesiologist) to receive the study drugs (over 10 minutes) half an hour before the induction of general anesthesia .The study solutions were prepared in identical syringes labeled "study drug",the anesthesia residents who administrated the study drug and who were in charge of general anesthesia and collecting the data were blinded to the study protocol).Group (C): the control group : received $100 \mathrm{ml}$ of normal saline IV .

Group (A1): received $2 \mathrm{mg} / \mathrm{kg}$ intravenous (IV) aminophylline diluted in $100 \mathrm{ml}$ normal [10].Group (A2): received $4 \mathrm{mg} / \mathrm{kg}$ intravenous (IV) aminophylline diluted in $100 \mathrm{ml}$ normal saline[ 11].At the operating room, monitors were applied (pulse oximetry,5leads ECG, end-tidal carbon dioxide, non-invasive arterial blood pressure .(the vital signs were continuously monitored to ensure homodynamic stability, normovolemia was also maintained), temperature probe and Bispectral index (BIS)electrodes were connected.Following preoxygenation; anaesthesia was induced by $2 \mu \mathrm{g} / \mathrm{kg}$ fentanyl, propofol infusion $30 \mathrm{mg} / \mathrm{kg} / \mathrm{h}$ till the BIS value of $48 \pm 2$ for 1 minute( to ensure adequate level of hypnosis)[12],lignocaine $1 \mathrm{mg} / \mathrm{kg}$ and $0.5 \mathrm{mg} / \mathrm{kg}$ atracurium to facilitate endotracheal intubation using cuffed oral tube. 
Anesthesia was maintained using sevoflurane $2 \%$ in $\mathrm{O}_{2}$ /air mixture and mechanical ventilation was adjusted to maintain the end-tidal carbon dioxide at 36-40 mmHg.Normothermia was maintained by warming the IV fluids and using hot air convection. At the end of the surgery, the inhalation of sevoflurane was discontinued, the neuromuscular block was reversed then the patients were extubated and after recovery they were transferred to the PACU.

The following data were recorded:

- Demographic data (age,sex,weight),ASA physical status (I or II) and duration of anesthesia and surgery

- Vital signs:heart rate and mean arterial blood pressure were monitored continuously, and recorded before and after study drug administration, after induction of general anesthesia then every 30 minutes for the duration of surgery(to maintain hemodynamic stability and euvolemia)

- Adverse events after aminophylline administration(e.g.light-headedness,vomiting,chest discomfort ,arrhythmia,hypotension or hypertension).

- The primary out come:the ROC (in minutes), which is the time after discontinuation of anesthesia till the response to a verbal command by eyes opening, time from propofol injection to the end point of hypnosis (defined as sustained BIS value of $48 \pm 2$ for $1 \mathrm{~min}$ ), the secondary out comes :time for BIS value to reach 80 after sevoflurane discontinuation [12], propofol dose $(\mathrm{mg})$ till BIS $48 \pm 2$, time to tracheal extubation (in minutes) (which is the time from cessation of anaesthetic agent and recovery from neuromuscular blockage clinically, and monitored by a nerve stimulator),time to discharge from the PACU ( in minutes) (which is the time from arrival of the patient to the PACU till the modified Aldrete score reached $\geq 9$ points.

- intraoperative cardiovascular complications(e.g.sinus tachycardia :20\% increase in the heart rate from the baseline reading ,hypotension or hypertension :20\% increase/decrease in the mean arterial pressure from the base line reading, in case of tachycardia or hypertension the depth of anesthesia was increased by increasing the concentration of the inhalational anesthetics and administration of fentanyl 50 ug IV, in case of hypotension ; the concentration of the inhales anesthetic was reduced, and ephedrine was administrated in $5 \mathrm{mg} / \mathrm{kg}$ increments, and causes of hypotension were excluded as intraoperative bleeding)

- the need for vasopressors or inotropes and fentanyl dose (ug)

\section{Statistical analysis}

Sample size calculation was done using the comparison of time to ROC,as reported in previous publication (5), the mean $\pm S D$ of time to ROC in normal saline group was $12.2 \pm 4.73$ minutes, in $6 \mathrm{mg} / \mathrm{kg}$ aminophylline group it was $6.18 \pm 3.96$ minutes.No results were found in the published literatures on lower dose of aminophylline. Therefore we assumed that the effect of $6 \mathrm{mg} / \mathrm{kg}$ is similar to the $4 \mathrm{mg} / \mathrm{kg}$, and the effect of the $2 \mathrm{mg} / \mathrm{kg}$ dose is half the $4 \mathrm{mg} / \mathrm{kg}$ dose effect, the minimum sample size was 13 patients in each group to be able to reject the null hypothesis with $80 \%$ power at $a=0.05$ level using one 
way analysis of variance test.The number of cases was increased to 15 in each group in case of drop of cases. G*Power software version 3.1.2 for MS Windows, Franz Faul, Kiel University.

Data were described in terms of mean \pm standard deviation, or frequencies. Numerical data were tested for the normal assumption using the Shapiro Wilk test. Comparison of numerical variables was done using one-way analysis of variance (ANOVA) test with Post-hoc multiple 2-group comparisons for comparing normally distributed data and Kruskal Wallis test with Post-hoc multiple 2-group comparisons for comparing not normal data. Categorical data were compared by Chi-square $\left(\chi^{2}\right)$ test. Ifthe expected frequency is $<5$. Fisher's" Exact test was used. $p$-values $<0.05$ was considered statistically significant.Statistical calculations were done using Statistical Package for the Social Science; IBM Corp, Armonk, NY, USA) release 22 for Microsoft Window.

\section{Results}

The study included 45 patients who underwent pelvi-abdominal surgeries [eg.abdominal exploration for intestinal obstruction, radicalcystectomy, radicalnephrectomy, splenectomy]; all patients completed the study; (figure1).

There was no statistically significant difference regarding the demographic data, ASA classification, duration of anesthesia or surgery among the study groups [Table 1]. The patients in the control group received less dose of propofol and fentanyl than those of aminophylline treated groups but this was not statistically significant. The time till BIS reach $48 \pm 2$ was highly significantly less for the control group than group A2 $(70.67 \pm 22.50,106.67 \pm 34.77$ seconds for group $C$ and $A 2$ respectively], $(p$-value $=0.00)$; [Table 1] 
Table 1

Demographic and operative data

\begin{tabular}{|lllll|}
\hline & $\begin{array}{l}\text { Group (C) } \\
(\boldsymbol{n}=\mathbf{1 5})\end{array}$ & $\begin{array}{l}\text { Group (A1) } \\
(\boldsymbol{n}=\mathbf{1 5})\end{array}$ & $\begin{array}{l}\text { Group (A2) } \\
(\boldsymbol{n}=\mathbf{1 5})\end{array}$ & P value \\
\hline Age (yr) & $45.07 \pm 6.08$ & $46.27 \pm 8.70$ & $42.73 \pm 9.55$ & 0.5 \\
\hline Weight (kg) & $77.13 \pm 10.04$ & $77.07 \pm 9.19$ & $77.67 \pm 21.28$ & 0.99 \\
\hline Sex(M/F) & $(9 / 6)$ & $(6 / 9)$ & $(10 / 5)$ & 0.31 \\
\hline ASA (I/II) & $(8 / 7)$ & $(9 / 6)$ & $(8 / 7)$ & 0.91 \\
\hline Operation time (min) & $176 \pm 30.19$ & $176 \pm 23.84$ & $176.33 \pm 36.37$ & 0.99 \\
\hline Anesthesia time (min) & $195.33 \pm 33.88$ & $195 \pm 20.96$ & $194.4 \pm 32.34$ & 0.99 \\
\hline Propofol(mg) & $176.67 \pm 31.99$ & $186 \pm 21.64$ & $190.67 \pm 17.91$ & 0.29 \\
\hline Fentanyl(ug) & $185.33 \pm 35.02$ & $198 \pm 31.21$ & $212.67 \pm 27.89$ & 0.07 \\
\hline Time to BIS 48 $\pm 2(\mathrm{sec})$ & $70.67 \pm 22.51$ & $90.36 \pm 34.77$ & $106.67 \pm 34.77$ & $0.28^{*}$ \\
& & & & $0.00^{\dagger}$ \\
& & & & $0.49^{\ddagger}$ \\
\hline
\end{tabular}

data are presented as mean \pm standard deviation $( \pm S D)$, or frequencies. ${ }^{*} p$ between $C$ and $A 1, \dagger$ between Cand A2 and łbetween A1 and A2.P-value < 0.05:statistically significant; P-value < 0.01:statistically highly significant.

There was no statistically significant difference in the heart rate or the MAP among the studied groups ( $p$ $>0.05$ ); [Tables 2 and 3 respectively]. 
Table 2

Heart rate (beat/min)

\begin{tabular}{|lllll|}
\hline & $\begin{array}{l}\text { Group (C) } \\
(\boldsymbol{n = 1 5 )}\end{array}$ & $\begin{array}{l}\text { Group (A1) } \\
(\boldsymbol{n = 1 5 )}\end{array}$ & $\begin{array}{l}\text { Group (A2) } \\
(\boldsymbol{n}=\mathbf{1 5})\end{array}$ & P value \\
\hline Before study drug administration & $83.6 \pm 17.37$ & $83.2 \pm 6.53$ & $83.73 \pm 6.54$ & 1 \\
\hline After study drug administration & $80.67 \pm 11.75$ & $80.2 \pm 4.02$ & $80.60 \pm 4.54$ & 1 \\
\hline After induction & $81.40 \pm 14.89$ & $81.47 \pm 6.40$ & $80.60 \pm 7.81$ & 1 \\
\hline At30 min. of surgery & $81.67 \pm 16.67$ & $82.33 \pm 7.33$ & $87.40 \pm 16.99$ & +0.84 \\
\hline At 60 min of surgery & $80.2 \pm 12.58$ & $82 \pm 6.84$ & $80.73 \pm 6.48$ & 1 \\
\hline At 90 min of surgery & $82.53 \pm 9.31$ & $82.13 \pm 4.99$ & $82.27 \pm 6.75$ & 1 \\
\hline At 120 min of surgery & $83.60 \pm 10.81$ & $82.73 \pm 5.72$ & $83.40 \pm 7.15$ & 1 \\
\hline At 150 min of surgery & $83.33 \pm 13.55$ & $83.80 \pm 5.62$ & $83.80 \pm 4.63$ & 1 \\
\hline At 180 min of surgery & $83.87 \pm 11.70$ & $84.33 \pm 6.41$ & $84.00 \pm 6.65$ & 1 \\
\hline
\end{tabular}

data are presented as mean \pm standard deviation $( \pm S D)$. ${ }^{*}$ between $C$ and $A 1,+$ between $C$ and $A 2$ and $\neq$ between $\mathrm{A} 1$ and $\mathrm{A} 2$. P-value $<0.05$ :statistically significant; $\mathrm{P}$ - value $<0.01$ :statistically highly significant.

Table 3

Mean arterial blood pressure $(\mathrm{mmHg})$

\begin{tabular}{|lllll|}
\hline & $\begin{array}{l}\text { Group (C) } \\
(\boldsymbol{n = 1 5 )}\end{array}$ & $\begin{array}{l}\text { Group (A1) } \\
(\boldsymbol{n}=\mathbf{1 5})\end{array}$ & $\begin{array}{l}\text { Group (A2) } \\
(\boldsymbol{n}=\mathbf{1 5})\end{array}$ & P value \\
\hline Before study drug administration & $84.8 \pm 17.35$ & $84.47 \pm 8.45$ & $83.73 \pm 6.64$ & 0.96 \\
\hline After study drug administration & $74.4 \pm 12.25$ & $75.13 \pm 5.68$ & $74.07 \pm 7.68$ & 0.94 \\
\hline After induction & $66 \pm 10.96$ & $66.33 \pm 6.02$ & $66.33 \pm 6.02$ & 0.94 \\
\hline At 30 min. of surgery & $80.93 \pm 8.98$ & $81.87 \pm 6.49$ & $82.40 \pm 6.39$ & 1 \\
\hline At 60 min of surgery & $81.13 \pm 7.13$ & $82.20 \pm 6.09$ & $81.93 \pm 9.06$ & 1 \\
\hline At 90 min of surgery & $81.80 \pm 5.67$ & $83.67 \pm 6.14$ & $83.40 \pm 9.20$ & 1 \\
\hline At 120 min of surgery & $82.27 \pm 4.72$ & $82.93 \pm 6.61$ & $82.80 \pm 9.56$ & 1 \\
\hline At 150 min of surgery & $82.73 \pm 5.97$ & $85.40 \pm 6.91$ & $84.00 \pm 8.90$ & 1 \\
\hline At 180 min of surgery & & & & 1 \\
\hline
\end{tabular}


data are presented as mean \pm standard deviation $( \pm S D) .{ }^{*}$ between Cand $A 1,+$ between $C$ and $A 2$ and $\neq$ between $\mathrm{A} 1$ and $\mathrm{A} 2$. P-value $<0.05$ :statistically significant; $\mathrm{P}$ - value $<0.01$ :statistically highly significant.

Time till BIS reached 80 was statistically significantly more for the control group compared to the study group ( $5.6 \pm 1.40,3.5 \pm 1.93$ and $2.53 \pm 1.72$ minutes for group $C, A 1$ and $A 2$, respectively, $p<0.00$ ), time for ROC was statistically significantly longer for the control group than group A1 andA2 $(8.93 \pm 0.92,5.6 \pm$ 2.47 and $4.53 \pm 3.33$ minutes and for group $C, A 1$ and $A 2$ respectively, $p$-value $=0.00$ ), the extubation time (min) was longer for the control group than group $A 1$ and $A 2$ and this was statistically highly significant $(12.4 \pm 1.08,7.87 \pm 3.27$ and $6.6 \pm 2.47$ for group $C, A 1$ and $A 2$ respectively; $p$-value $=0.00)$,the discharge time was not different among the study groups $(p>0.05)$; (Table 4).

Table 4

Recovery profile

\begin{tabular}{|lllll|}
\hline & $\begin{array}{l}\text { Group (C) } \\
(\boldsymbol{n = 1 5 )}\end{array}$ & $\begin{array}{l}\text { Group (A1) } \\
(\boldsymbol{n = 1 5})\end{array}$ & $\begin{array}{l}\text { Group (A2) } \\
(\boldsymbol{n}=\mathbf{1 5})\end{array}$ & P value \\
\hline Time till BIS 80(min) & $5.6 \pm 1.40$ & $3.5 \pm 1.93$ & $2.53 \pm 1.72$ & $0.00^{\star}$ \\
& & & & $0.00^{\dagger}$ \\
& & & & $0.07^{\ddagger}$ \\
\hline ROC (min) & $8.93 \pm 0.92$ & $5.60 \pm 2.47$ & $4.53 \pm 3.33$ & $0.00^{\star}$ \\
& & & & $0.00^{\dagger}$ \\
& & & & $0.14^{\ddagger}$ \\
\hline Extubation time (min) & $12.4 \pm 1.08$ & $7.87 \pm 3.27$ & $6.6 \pm 2.47$ & $0.00^{\star}$ \\
& & & & $0.00^{\dagger}$ \\
& & & & $0.12^{\ddagger}$ \\
\hline Discharge time (min) & $31.67 \pm 4.49$ & $28.33 \pm 6.47^{\star \ddagger}$ & $28.47 \pm 9.72^{\dagger \ddagger}$ & $0.64^{*}$ \\
& & & & $0.69^{\dagger}$ \\
& & & & $1.00^{\ddagger}$ \\
\hline
\end{tabular}

data are presented as mean \pm standard deviation $( \pm S D)$. ${ }^{*}$ between $C$ and $A 1,+$ between $C$ and $A 2$ and $\ddagger$ between $\mathrm{A} 1$ and $\mathrm{A} 2$. P-value $<0.05$ :statistically significant; $\mathrm{P}$ - value $<0.01$ :statistically highly significant.

No side effects related to administration aminophylline were reported and none of the patient required intraoperative administration of vasodilator/vasopresors or inotropes.

\section{Discussion}


The results of this study showed that premedication with aminophylline 2 or $4 \mathrm{mg} / \mathrm{kg} \mathrm{IV}$ reduced time till BIS reached 80after discontinuation of anesthesia,time of ROC and the extubation time without affecting the discharge time compared to the control group and without statistically significant differences between the groups treated by aminophylline 2 or $4 \mathrm{mg}$.Aminophylline is a non-selective adenosine receptor antagonist used for treatment of asthma and chronic obstructive pulmonary disease [13] and it has been used to antagonize the effects of anesthetic and analgesic agents [14].Its neuronal excitability is due to the inhibition of gamma-Aminobutyric acid and central adenosine receptors [15].Adenosine is involved in sleep and has a sedative and hypnotic effect $[5,16,17,18]$,its systemic administration enhanceshypnosis induced by IV anesthetics and decreased intraoperative anesthetic requirements[19].Perfusion of A1 receptor-selective antagonists as caffeine or theophylline increases wakefulness, in the study of Turan et,al[5] the LOC was prolonged by aminophylline compared with saline in volunteers who were given aminophylline $6 \mathrm{mg} / \mathrm{kg} \mathrm{IV,followed} \mathrm{by} 1.5 \mathrm{mg} / \mathrm{kg} / \mathrm{h}$; time to LOC was $7.7 \pm$ $2.03 \mathrm{~min}$ for the volunteer group versus $5.1 \pm 0.75 \mathrm{~min}$ for the saline group and the time to ROC was shorter $6.18 \pm 3.96 \mathrm{~min}$. for the volunteer group versus $12.2 \pm 4.73 \mathrm{~min}$ for the saline group, $P=0.03$ ) which coincides with the results of this study,Turan et al (5) also reported that the propofol dose at LOC was larger with aminophylline treated group which was reported in the presented study and they reported that the minimum bispectral indexwas greater with aminophylline more than the saline group ( $51 \pm 15 \mathrm{vs}$ $38 \pm 9, P=0.03$ ). Turan et al (3) concluded that the recovery from sevoflurane anesthesia and BISscores were improved in early period when aminophylline wasgiven at emerging from anesthesia.Ghaffaripour et al(20) concluded that injection of aminophylline at emergence time significantly increased BIS and reduced the recovery time in patients anesthetized with total intravenous anesthesia. M. Hu et al (21) reported that the administration of aminophylline $3 \mathrm{mg} / \mathrm{k}$ was associated with significant increases in BISafter discontinuation of sevoflurane anesthesia for the control group compared to the study groups. The ability of aminophylline to decrease the anesthetic effects of propofol can be explained by its antihypnotic effect or its hemodynamic changes that affect the transfer of propofol to the brain [5].. Sakurai et., al. suggested that the sedative/hypnotic effects of propofol can be explained by central adenosinergic mechanisms because ATP potentiated the sedative/hypnotic actions of propofol while aminophylline reverse this effect[6].Aghabiklooeiet[22] showed that intravenous aminophylline improved consciousness and respiration by antagonizing sedation induced by benzodiazepines $\mathrm{n}$ this study the extubation time was longer for the control group than groups who received 2 or $4 \mathrm{mg} / \mathrm{kg}$ of aminophylline $(12.4 \pm 1.08,7.87 \pm 3.27$ and $6.6 \pm 2.47$ for group $A, B$ and $C$ respectively; $p$-value $=0.00)$, the discharge time was not different among the study groups $(p>0.05)$,these results coincide with those of Farsadlmani et., al [23] who concluded that the extubation times was decreased but not the discharge time for patients who received 1 or $5 \mathrm{mg} / \mathrm{kg}$ of aminophylline compared to the control group after laparotomy. El Tahan [11] gave aminophylline after the end of surgery and reported that the patients receiving 2, 3, 4 or $5 \mathrm{mg} / \mathrm{kg}$ of aminophylline had shorter times to extubate and to home discharge compared to the control group.The differences between the results of the present study and other studies could be explained by different doses of aminophylline and time of its administration also some of the previous studies were on volunteers as in the study of Turan et al(5).Also the study of Sakurai et al[6] was only on 2 cases where 
$5 \mathrm{mg} / \mathrm{kg}$ IV aminophylline was administrated in the postoperative period to reverse propofol-induced sedation and the study of Turan et al (3) was on day- case surgeries

\section{The Limitation Of This Study}

The small sample size, so further studies are recommended in a different surgical situations and on larger number of patients to confirm the effect of aminophylline to enhance recovery and speed discharge from the PACU.

\section{Conclusion}

Premedication with aminophylline 2 or $4 \mathrm{mg} / \mathrm{kg}$ enhances the recovery profile after pelvi-abdominal surgeries under general anesthesia compared to the control group and cardiovascular complications were not reported.

\section{Abbreviations}

ANOVA : Analysis Of Variance

ASA: American Society of Anesthesiology

ATP: Adenosine Tri Phosphate

BIS: BiSpectral Index

ECG : Electrocardiogram

HR: Heart Rate

IV: Intravenous

MAP: Mean Arterial Pressure

LOC :Loss Of Consciousness

PACU : Post-Anesthesia Care Unit

ROC: Recovery Of Consciousness

SD: Standard Deviation

\section{Declarations}

\section{Ethics approval and consent to participate}


The study protocol was approved by the ethical committee of Faculty of Medicine, Beni -Suef University (FM-BSU),(FMBSUREC/01102019/Rashwan) and written informed consent was obtained to participate in this study .

\section{Consent for publication}

Not applicable

\section{Clinical Trial registration}

Name of the registry: Register@ClinicalTrials.gov

Trial registration number ClinicalTrials.gov Identifier: NCT04151381

Date of registration, : November 5, 2019, 'Retrospectively registered'

URL of trial registry record: https://clinicaltrials.gov/ct2/show/NCT04151381

\section{Availability of data and materials}

The datasets generated during and/or analyzed during the current study are not publicly available due to confidentiality of Faculty of Medicine, Beni -Suef University files but are available from the corresponding author on reasonable request.

\section{Authors' contributions}

S A. put the design, shared in the clinical part and in collecting the background resources and in writing the manuscript, MHB. shared in writing and revising the manuscript, MA. and DR. shared in writing the manuscript and revising the data. All authors read and approved the final manuscript.

\section{Competing interests}

The authors declare that they have no competing interests.

\section{Funding}

The authors received no financial support.

\section{Acknowledgments}

We would like to acknowledge Ashraf Abel Mawgood and Ahmed Badawy for the final revision and their valuable comments.

\section{References}


1. Niemand D, Martinell S, Arvidsson S, Ekström-Jodal B, Svedmyr N. Adenosine in the inhibition of diazepam sedation by aminophylline. Acta Anaesthesiol Scand 1986;30(7):493-495.

2. Krintel J.J. and Wegmann F. Aminophylline reduces the depth and duration of sedation with barbiturates. Acta Anaesthesiologica Scandinavica 1987; 31: 352-354.

3. Turan A, Memiş D, Karamanlioglu B, Colak A, Pamukçu Z, Turan N. Effect of aminophylline on recovery from sevoflurane anesthesia. Eur J Anaesthesiol 2002;19(6):452-454.

4. Stirt J.A. Aminophylline may act as a morphine antagonist. Anesthesia 1983;38:275-278.

5. Turan A, Kasuya y , Govinda R ,Obal R,Desa R,Stefan D,et al.The effect of aminophylline on loss of consciousness, bispectral index, propofol requirement, and minimum alveolar concentration of desflurane in volunteers. Anesth Analg $2010 ; 110(2): 449-454 i$.

6. Sakurai S, Fukunaga A, Fukuda K, Kasahara M, Ichinohe T, Kaneko Y. Aminophylline reversal of prolonged postoperative sedation induced by propofol. J Anesth 2008; 22(1):86-88.

7. Piafsky KM and Ogilvie RI. Dosage of theophylline in bronchial asthma. N Engl J Med 1975;292(23):1218-1222.

8. Stirt JA. Aminophylline is a Diazepam Antagonist. Survey Anesthesio/ 1982;26(4):214.

9. Turan A, Memiş D, Karamanlýodthlu B, Pamukçu Z, Süt N. Effect of aminophylline on bispectral index. Acta Anaesthesiol Scand 2004;48(4):408-411.

10. Gürel A, Elevli M,Hamulu A. Aminophylline reversal of flunitrazepam sedation. Anesth Analg 1987;66(4):333-336.

11. El Tahan MR. Effects of aminophylline on cognitive recovery after sevoflurane anesthesia. $J$ Anesth 2011;25(5):648-656.

12. Arya S, Asthana V, Sharma JP. Clinical vs. bispectral index-guided propofol induction of anesthesia: A comparative study. Saudi J Anaesth 2013 ; 7(1): 75-79.

13. Hoshino T, Toda R, Aizawa H. Pharmacological treatment in asthma and COPD. Allergol Int 2009;58(3):341-346.

14. Zhang JM, Wang F, Xin Z, Lü H. Zhonghua Yi Xue Za Zhi. Effectiveness of Bispectral index in intravenous anesthesia with remifentanil and propofol in children. Chinese Medical Journal 2008 88(41) :2904-2906.

15. Huang ZL, Qu WM, Eguchi N, Chen JF, Schwarzschild MA, Fredholm BB etal. Adenosine A2A, but not A1, receptors mediate the arousal effect of caffeine. Nat Neurosci. 2005 Jul;8(7):858-9. doi: 10.1038/nn1491. PMID: 15965471.

16. Basheer R, Strecker RE, Thakkar MM, McCarley RW. Adenosine and sleep-wake regulation. Prog Neurobio/ 2004;73(6):379-396.

17. Diana Tanase, Helen A. Baghdoyan, Ralph Lydic.Dialysis Delivery of an Adenosine $A^{1}$ Receptor Agonist to the Pontine Reticular Formation Decreases Acetylcholine Release and Increases Anesthesia Recovery Time. Anesthesiology2003;98(4):912-920. 
18. Tung A, Herrera S, Szafran MJ, Kasza K, Mendelson WB. Effect of sleep deprivation on righting reflex in the rat is partially reversed by administration of adenosine $\mathrm{A} 1$ and $\mathrm{A} 2$ receptor antagonists. Anesthesiology 2005;102(6):1158-1164.

19. Kaputlu I, Şadan G, Özdem S.Exogenous adenosine potentiates hypnosis induced by intravenous anaesthetics.Anesthesia1988; 53: 496-500

20. Ghaffaripour S, Khosravi MB, Rahimi A, Sahmedini MA, Chohedri A, Mahmoudi H, et al. The effects of Aminophylline on clinical recovery and bispectral index in patients anesthetized with total intravenous anesthesia. Pak J Med Sci 2014;30(6):1351-1355

21. Hüpfl M, Schmatzer I, Buzath A, Burger H, Hörauf K, Ihra G et.,al. The effects of aminophylline on bispectral index during inhalational and total intravenous anesthesia. Anesthesia 2008;63: 583-587

22. Aghabiklooei A. The Efficacy of Aminophylline in Raising Consciousness in BenzodiazepinesIntoxicated Patients. Asia Pac J Med Toxicol 2018;7:17-9.

23. Imani F, Ahmadi Tabatabaei A, Shariat Moharari R, Etezadi F, Pourfakhr P. A Comparison of the Effects of Low and High Doses of Aminophylline on Recovery Time and the Bispectral Index Score Following Isoflurane Anesthesia. Iran Red Crescent Med J 2017 ; 19(2):e32763

\section{Figures}




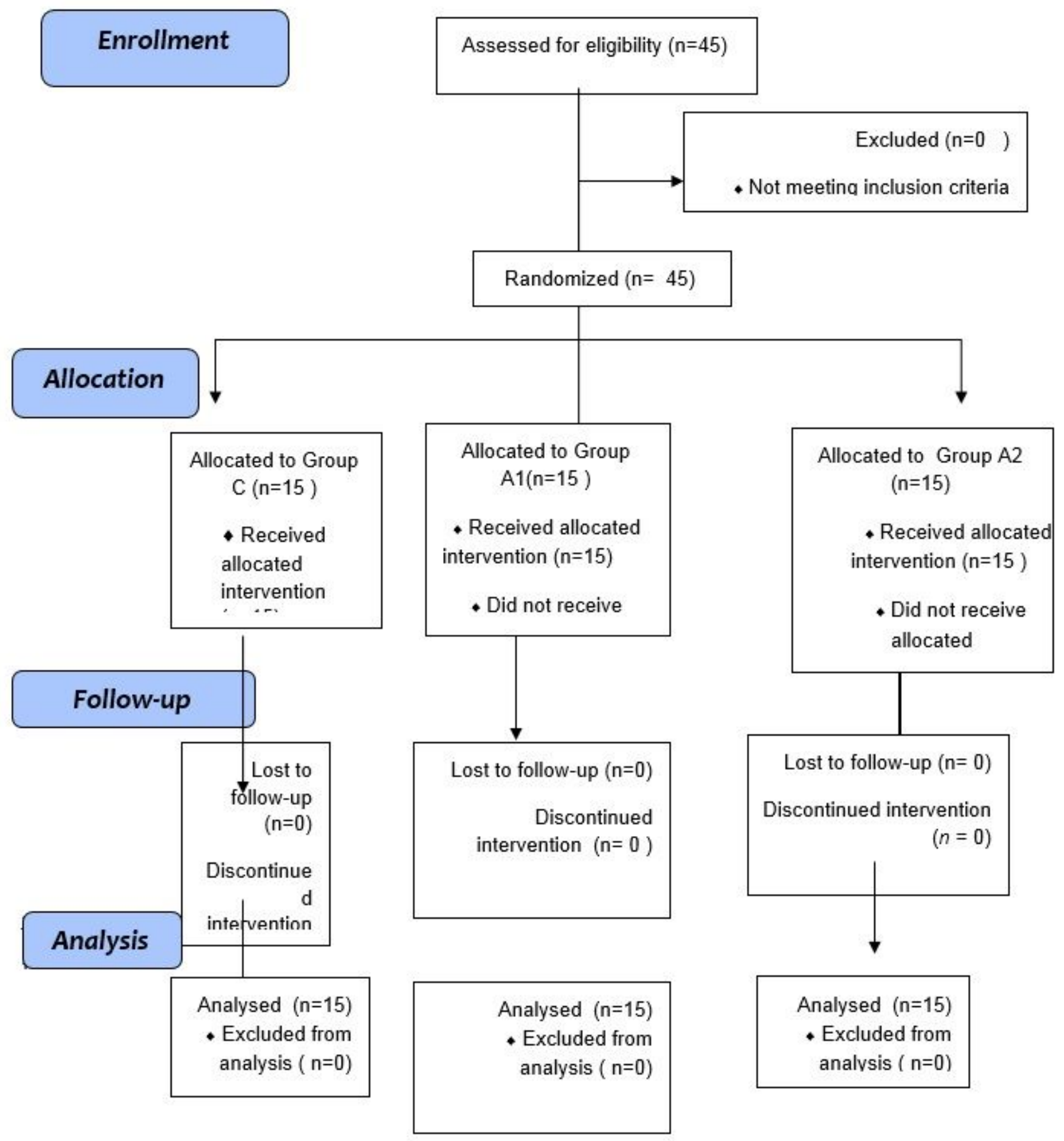

Figure 1

Consort flow participant diagram

\section{Supplementary Files}

This is a list of supplementary files associated with this preprint. Click to download. 
- CONSORT2010Checklist.doc

Page 15/15 